\title{
Reinstatement of fear responses in human aversive conditioning
}

\author{
Dirk Hermans*, Trinette Dirikx, Debora Vansteenwegenin ${ }^{\dagger}$, Frank Baeyens, \\ Omer Van den Bergh, Paul Eelen \\ Department of Psychology, University of Leuven, Tiensestraat 102, 3000 Leuven, Belgium
}

Accepted 18 March 2004

\begin{abstract}
The treatment of choice for a number of anxiety disorders is exposure therapy. However, successful reduction of fear through exposure is sometimes followed by a (partial) return of symptoms of fear (return of fear, ROF; Clin. Psychol. Rev. 9 (1989) 147). Several possible learning mechanisms have been suggested to explain ROF (e.g. mechanisms related to spontaneous recovery, renewal, reacquisition and reinstatement). The present study focuses on reinstatement, which refers to the observation that mere US-only presentations can 'reinstate' previously extinguished fear responses. Although animal research has repeatedly demonstrated this phenomenon, little is known about fear reinstatement in humans. The present study employed a differential aversive conditioning procedure: after acquisition and a subsequent extinction procedure, a series of four unpredicted US-only trials was scheduled in the reinstatement group. The control group did not receive additional US presentations. A significant reinstatement effect was observed for US-expectancy ratings and fear ratings in the reinstatement group, but not in the control group. No differences were observed in a reaction time measure of resource allocation to the conditioned stimuli. These findings constitute a first demonstration of reinstatement of conditioned fear responses in humans. Implications for exposure treatment and suggestions for future research are discussed.
\end{abstract}

(C) 2004 Elsevier Ltd. All rights reserved.

Keywords: Classical conditioning; Fear; Reinstatement; Renewal

\footnotetext{
${ }^{*}$ Corresponding author. Tel.: + 3216325963 ; fax: + 3216325924 .

E-mail address: dirk.hermans@psy.kuleuven.ac.be (D. Hermans).

${ }^{\dagger}$ Deborah Vansteenwegen is a post-doctoral researcher of the Fund for Scientific Research FWO-Vlaanderen.
} 


\section{Introduction}

For several anxiety disorders, exposure therapy is the treatment of choice. This is definitely true for simple phobias (e.g. Öst, 1989), but meta-analyses indicate that repeated confrontation (i.e. exposure) with the object(s) of fear is also highly effective in the treatment of social phobia (Taylor, 1996; see also Feske \& Chambless, 1995), of agoraphobia and of panic disorder with and without agoraphobia (Clum, Clum, \& Surls, 1993; Cox, Endler, Lee, \& Swinson, 1992; Trull, Nietzel, \& Main, 1988). Also for obsessive-compulsive disorder (Cox, Swinson, Morrison, \& Lee, 1993) and post-traumatic stress disorder (Abramowitz, 1996) the effectiveness of exposure treatment is well-documented through meta-analyses of treatment outcome studies.

Despite the treatment's efficacy, fear may return with the passage of time. For a small but consistent proportion of seemingly successfully treated patients, there is partial (or full) reappearance of fear at follow-up. This phenomenon is referred to as 'return of fear' (ROF, Rachman, 1979, 1989) and poses a challenge for both research and clinical practice. Not only is it important to know how exposure treatment can be optimized to reduce the risk of relapse (secondary prevention), but from a theoretical perspective it is also crucial to understand the mechanisms by which previously reduced fears reappear.

When one views clinical fear as resulting from a process of associative learning (e.g. Davey, 2002), the study of the mechanisms that drive ROF can be translated into a classical conditioning context. According to modern conditioning theories of fear, the contingent presentation of an originally neutral stimulus (e.g. an elevator) together with a threatening event (e.g. a panic attack) will lead to the formation of an association between the memory representations of both stimuli/ events. Subsequent confrontation with the conditioned stimulus (CS) will reactivate the memory representation of the unconditioned stimulus (US) as well as the fear that is associated with the latter event. The contemporary cognitive model of human classical conditioning provides a rich conceptual framework for the understanding of the aetiology, maintenance and treatment of human fears and phobias (e.g. Bouton, Mineka, \& Barlow, 2001; Davey, 1992, 1997; Eelen, Hermans, \& Baeyens, 2001).

From this perspective, exposure can be conceptualized as a clinical analogue of extinction (i.e. CS-only presentations after acquisition). Research on the mechanisms of ROF after exposure can thus be translated to the study of the return of classically conditioned fear responses after extinction. Whereas older formal models of classical conditioning assumed that an extinguished CS regained the 'virginal status'-both in terms of is behavioural impact and of its informational value - of a stimulus that has never entered into the association with a US, evidence from the animal laboratory strongly argues against this 'extinction-implies-unlearning' position. These studies demonstrate that although an extinction procedure results in a decrease of conditioned responses, it does not destroy the underlying association. In fact, animal work by Rescorla (1996) has even shown that extinction leaves the original CS-US association intact. According to these more recent views, what happens during extinction is that new associations are added to the existing one. These second-learned associations can be viewed as 'exceptions-to-the-rule' and are more context-dependent. Experimental evidence for this view is reviewed by Bouton (Bouton, 1988, 1998; Bouton \& Swartzentruber, 1991). When these insights are applied to the example of the patient who developed a fear for elevators on the basis of a past contingency with panic attacks, it is assumed that in spite of a clinically significant reduction of fear and avoidance, 
exposure treatment (i.e. multiple CS-only presentations) will leave the original memory association between the CS (elevator) and the US (panic attack) intact. This association remains dormant and can later be a source of ROF.

Animal research has revealed a number of post-extinction events that might reactivate the original CS-US association. These include the mere passage of time (spontaneous recovery), introduction of the $\mathrm{CS}$ in a context that is different from the extinction context (renewal), confrontation with unpredicted presentations of the US (reinstatement) and confrontation with one or more contingent presentations of the CS and the US (reacquisition). The study of these phenomena can inform us about the mechanisms that drive ROF, as well as of the procedures that could aid in minimizing this return in clinical practice.

A good example is research on renewal of extinguished conditioned fear responses. Renewal refers to the observation that when a CS that was completely extinguished in a context (B) different from the acquisition context (A), is reintroduced in the acquisition context (A) or even another context $(\mathrm{C})$, a recovery or renewal of conditioned responding towards the CS can be observed (e.g. Bouton \& Bolles, 1979; Vansteenwegen et al, 2003). This demonstrates that the organism has not 'unlearned' the CS-US association, but instead has learned that 'in this particular context the CS-US relation does not hold'. The CS becomes an ambiguous stimulus, the meaning of which becomes dependent on contextual stimuli. While the original CS-US association remains, a new piece of information is added, and these new associations are contextdependent. These animal studies on renewal have inspired researchers to investigate the possible role of renewal as a source of ROF after successful exposure treatment. Mineka, Mystkowski, Hladek, and Rodriguez (1999), for instance, offered a session of exposure therapy to a group of participants who were highly afraid of spiders. When one week later these persons were tested in the same or a different context, the participants who were tested in a novel context showed more ROF (see also Mystkowski, Craske, \& Echiverri, 2002). Based on these findings, it is but one step to investigate how such context-dependent ROF can be reduced or prevented. Animal research suggests a number of possibilities, of which exposure to multiple contexts is just one (e.g. Gunther, Denniston, \& Miller, 1998). In search of the mechanisms that drive ROF, the study of renewal thus indicates that context-shifts might be an important factor. Given that original associations are not 'unlearned' and that second-learned information (e.g. based on extinction) is highly context-dependent, contexts will influence the type of information that is retrieved from the 'fear structure', and will thus influence the possible re-emergence of fear.

Besides renewal, Bouton (Bouton, 1988; Bouton \& Swartzentruber, 1991) has identified reinstatement as a second possible source of relapse after extinction. In a reinstatement procedure, a previously conditioned stimulus is first extinguished until conditioned responding disappears. Next, a few USs are administered in the absence of the CS. When the previously extinguished CS is finally re-presented, conditioned responding to the CS (partially) re-appears (e.g. Bouton \& Bolles, 1979; Rescorla \& Heth, 1975). It is assumed that the US-only presentations 'reinstate' the CS-US association that is present but dormant after extinction. The reinstatement of conditioned responses has been observed in several types of conditioning procedures, including appetitive conditioning (Bouton \& Peck, 1989) and taste aversion learning (Schachtman, Gustavson, Chelonis, \& Bourne, 1992). Most evidence, however, stems from fear conditioning studies with animals, in which the reinstatement is observed of previously extinguished fear responses like freezing (e.g. Westbrook, Iordanova, McNally, Richardson, \& Harris, 2002) or avoidance 
behaviour (e.g. Richardson, Duffield, Bailey, \& Westbrook, 1999). Although there is no final agreement on how reinstatement is best explained at a process level (Delamater, 1997), the effects of reinstatement have been repeatedly replicated in animal research. They rarely involve a complete restoration of the fear, but reinstatement effects are quite robust and can be observed after very few US presentations and after fairly extensive extinction exposure to the CS.

In contrast with the animal literature, research on reinstatement in humans is scarce. The very few studies that have investigated reinstatement in humans are situated in causal learning research (García-Gutiérrez, \& Rosas, 2003) and in studies on reinforcement in mentally disabled children and adolescents (Spradlin, Fixsen, \& Girardeau, 1969; Spradlin, Girardeau, \& Hom, 1966). To our knowledge, the only study that investigated reinstatement in the context of fear conditioning in humans is reported by Rachman and Whittal (1989). In the first phase of this study (session 1), a group of forty snake- or spider-phobic individuals was subjected to an exposure treatment. Two weeks later, all participants were invited for a retest session. On this occasion half of the participants received an electric shock (reinstatement group). The control group was connected to the same equipment, but did not receive a shock. This manipulation did, however, not influence the amount of ROF that was assessed later on in this second session. As was pointed out by the authors, the absence of a reinstatement effect might have been due to the fact that the reinstatement manipulation was not sufficiently strong (presence or absence of shock at the start of session 2). More fundamentally, however, it is debatable whether a shock can function as a reinstatement US for the reinstatement of fear for snakes and spiders. Even though Rescorla and Heth (1975) demonstrated that reinstatement is possible with a US, that is, qualitatively different from the US that is used during the acquisition of the fear (footshock versus aversive noise), this finding has not been repeatedly replicated. Moreover, it remains unclear how the original US in the acquisition of the fear of snakes/spiders for these participants should be conceptualized.

Given the theoretical and clinical importance of knowledge concerning the mechanisms that drive ROF, it is surprising how little research has been conducted on reinstatement in humans. In this context, the main aim of the present study was to investigate whether evidence for reinstatement can be obtained using a fear conditioning procedure with human participants. The conditioning preparation that was used, was a differential conditioning procedure with pictures of neutral human faces as CS + and CS- and an aversive electrocutaneous stimulus as the US (Hermans, Crombez, Vansteenwegen, Baeyens, \& Eelen, 2002a; Hermans, Spruyt, \& Eelen, 2003). After the acquisition phase, a lengthy extinction procedure was implemented. Subsequently, for half of the participants (reinstatement group) a series of four unpredicted US-only trials was presented. The control group did not receive any additional USs. Effects of the reinstatement manipulation were assessed using verbal ratings of US-expectancy and fear, and using a secondary probe reaction time task (Dawson, Schell, Beers, \& Kelly, 1982). For this task, tone probes are presented during the $\mathrm{CS}+$ and $\mathrm{CS}-$, and participants are simply asked to respond as fast as possible to the probes by pressing a key. Previous research has shown that responses to the tones that are presented during the CS + are typically slowed after conditioning (Dawson et al., 1982; Lipp, Siddle, \& Dall, 1993). This is assumed to reflect the allocation of processing resources to this stimulus.

If we are able to show an effect of our manipulation, this would be a first demonstration of reinstatement of fear responses in humans. Subsequent studies can then employ this laboratory analogue of the return of clinical fear, to study the learning mechanisms that are responsible for 
fear reinstatement, as well as to investigate the effectiveness of a number of procedures to prevent/ reduce ROF. An advantage of this laboratory model is that it allows to present US-type stimuli to the participants (i.e. after informed consent); which is because of ethical reasons obviously (less or) not possible in more clinical designs (e.g. panic attack or trauma as US).

\section{Method}

\subsection{Participants}

Thirty first-year psychology students (all women) participated for partial fulfillment of course requirements. All participants gave informed consent and were instructed that they could decline further participation at any time during the experiment.

\subsection{Materials}

The pictures that were used as $\mathrm{CS}+, \mathrm{CS}_{-}$, or as neutral filler stimuli were selected on an individual basis from a set of 20 color pictures of human faces. Half of the pictures in this set showed the face of a man, while the other half showed the face of a woman. Pictures varied in the age of the portrayed persons and in their affective expression. None of the faces displayed a strong emotional expression. These stimuli are part of a larger set of stimuli that has been used in previous conditioning studies (e.g. Hermans, Crombez, Vansteenwegen, Baeyens, \& Eelen, 2002a; Hermans, Vansteenwegen, Crombez, Baeyens, \& Eelen, 2002b). All photographs were digitized as 256 colors, $500 \times 340$ resolution jpeg files. They were always presented $10 \mathrm{~cm} \times 14 \mathrm{~cm}$ against the black background of the computer monitor.

Electrocutaneous stimuli with duration of $1500 \mathrm{~ms}$ were delivered by means of Fukuda standard $\mathrm{Ag} / \mathrm{AgCl}$ electrodes (1.2 cm diameter). The electrodes were filled with electrode gel and were attached to the left wrist. A $2000 \mathrm{~ms}, 1000 \mathrm{~Hz}$ tone that was played through the computer loudspeakers was employed during the secondary probe reaction time task.

Presentation of all stimuli and rating scales, as well as the registration of all responses (including response latencies) was controlled by an object-oriented, pool-based, real-time and millisecond accurate program that was developed with $\mathrm{C}++$ for the Windows platform (Affect 1.0; Hermans, Baeyens, \& Claryse, 2000). The experiment was run on an IBM compatible Pentium IV computer with a 17 in SVGA monitor.

\subsection{Procedure}

The experiment consisted of five major phases: the stimulus selection phase, the acquisition phase, the extinction phase, the reinstatement phase and the post-reinstatement test phase. When the participant entered the lab the individual stimulus selection and use of the electrocutaneous stimulus was explained in detail. The experiment started after the participant had given informed consent.

Stimulus selection phase: During this phase, the $\mathrm{CS}+, \mathrm{CS}-$ and filler stimuli were selected on the basis of individual ratings. First, all pictures were presented once in random order on the 
computer screen (duration: $2 \mathrm{~s}$ each). This was done to familiarize the participants with all visual stimuli. Next, participants provided evaluative ratings. We used a 21-point rating scale with -100 (very unpleasant), 0 (neutral), and 100 (very pleasant) as anchors. Participants indicated their ratings by shifting a pointer on the scale that was presented below each picture. Written and verbal instructions stressed that they should rely on their first, spontaneous reaction towards the picture. After the evaluative ratings, we asked the participants to provide fear ratings for all stimuli. Fear was expressed on an 11-point rating scale (Fear Thermometer) that ranged from 0 (not fearful at all) to 10 (very fearful). Written and verbal instructions requested to indicate the amount of fear that was felt when looking at the stimulus. Stimuli were rated again in random order.

When all 20 pictures had been evaluated for valence (ER1, Evaluative Rating 1) and fear (FR1, Fear Rating 1), the participant was invited to fill out the Dutch version (Hermans, 1997) of the Need to Evaluate Scale (NES; Jarvis \& Petty, 1996), which was used as filler task. Meanwhile, out of the participant's sight, the experimenter selected six neutrally rated stimuli. First, pictures with a ' 0 ' score on the evaluative dimension (ER1) were selected. If this category did not contain six stimuli, pictures were selected from the categories ' -10 ' and ' +10 ', and so on. When these criteria resulted in a set with more than six stimuli, the stimuli with the lowest fear ratings in the set were selected. On a random basis, two stimuli were designated as CS + and CS-, and four stimuli as neutral filler stimuli that will also be used in the ratings.

During the second part of the stimulus selection phase, the intensity of the US was determined. The wrist of the nondominant hand was cleaned with Brasivol $\mathrm{Nr} 1$ peeling cream. The electrodes were attached, and remained attached during the rest of the experiment. Next, during a work-up procedure, the experimenter gradually increased the level of the presented electrocutaneous stimuli until the participant reported that it was 'unpleasant and demanding some effort to tolerate'. This stimulus was used as the US in the acquisition phase as well as during the reinstatement phase.

Acquisition phase: The participant was invited to take place at a distance of about $60 \mathrm{~cm}$ from the computer screen. They were informed that two stimuli would be presented, one of which would always be followed by the electrocutaneous stimulus, while the second stimulus would never be followed by this US. They were also instructed to remain attentive during the stimulus presentations and to respond as fast as possible to the tone probes by pressing the space bar on the keyboard with their dominant hand. The CS + and the CS - were each presented 12 times for the duration of $7 \mathrm{~s}$. The CS + was always followed by the presentation of the US, which was presented $1500 \mathrm{~ms}$ after the offset of the CS + . The CS- was never followed by the US. During this series of 24 acquisition trials (12 CS $+/ 12 \mathrm{CS}-$ ), tone probes were presented during 4 of the $\mathrm{CS}+$ presentations and 4 of the $\mathrm{CS}-$ presentations. Both in the case of the CS + and the $\mathrm{CS}-$, two of these probes were presented $300 \mathrm{~ms}$ after CS onset (early probe), while the two other probes were presented $6000 \mathrm{~ms}$ after CS onset (late probe). ${ }^{1}$ The order of the presentation of the 24 acquisition trials was randomized, with the exception that the first two trials consisted of a CS + trial and a CS- trial (without probe). The order of these two trials was counterbalanced across participants. The mean inter trial interval (ITI) was $3500 \mathrm{~ms}$ (range $2000-5000 \mathrm{~ms}$ ).

\footnotetext{
${ }^{1}$ In the original study of Dawson et al. (1982) the probe position (early versus late probes) was manipulated to investigate different elements of the response to the conditioned stimulus (orientation versus preparation).
} 
After the acquisition trials, contingency awareness was assessed. First, participants were shown the 6 pictures (including $\mathrm{CS}+, \mathrm{CS}-$ and the four fillers) and were asked to indicate for each of these stimuli whether or not it had been presented during the previous phase (i.e. the acquisition trials). If participants correctly identified the two CSs, these two stimuli were shown again, and the participant was asked to indicate whether these stimuli had been followed by the US during the acquisition phase. Participants who were not aware of the crucial CS $+/ \mathrm{US}$ and CS $-/-$ contingency were debriefed and thanked. ${ }^{2}$ Participants who were contingency aware were next asked to provide $U S$-expectancy ratings for the $\mathrm{CS}+$ and $\mathrm{CS}-$. This was assessed by indicating to what extent they had expected a US following the presentation of the $\mathrm{CS}+$, and following the presentation of the $\mathrm{CS}-$ during the last trials of the acquisition phase. This 11-point graphic rating scale was anchored by 'not at all' (0) and 'very much' (100). It was explained that this question did not pertain to the extent to which the CS 'made them think of the US', but only applied to the extent to which they had expected the US. Subsequently, the participant was asked to rate each of the six pictures for a second time on the evaluative dimension (ER2) and the Fear Thermometer (FR2). ${ }^{3}$ It was stressed that their rating could have remained the same or could have changed as compared to their previous ratings during the stimulus selection phase (ER1 and FR1), and that we were only interested in how they rated these stimuli at this very moment.

Extinction phase: This part of the experiment consisted of three blocks of 24 extinction trials. Hence, the number of extinction trials was three times the number of acquisition trials. The presentation parameters for each block were the same as for the acquisition blocks, with the only exception that no USs were presented. Hence, each block comprised 12 unreinforced CS + presentations and 12 unreinforced $\mathrm{CS}-$ presentations. Within each block, tone probes were presented during four of the $\mathrm{CS}+$ and four of the $\mathrm{CS}-$ presentations (two early probes, two late probes). The order of the presentations was randomized for all three extinction blocks. As this was the case for the first acquisition block, the first two trials of the first extinction block consisted of $1 \mathrm{CS}+$ trial and $1 \mathrm{CS}-$ trial (without probe). Half of the participants started with a CS + trial. The ITI was the same as during acquisition. Although no electrocutaneous stimuli were given during this phase of the experiment, the electrodes remained attached. Also, participants were not informed that the CS + would no longer be followed by the US.

After the extinction trials, US-expectancy and fear ratings (FR3) were again assessed for the $\mathrm{CS}+$ and $\mathrm{CS}-$. These ratings referred to the last presentations of the CSs. In addition, evaluative ratings (ER3) were provided for the set of six stimuli (CS +, CS-, 4 fillers). It was explained that

\footnotetext{
${ }^{2}$ In line with previous studies (Hermans et al., 2002a, b), contingency awareness was considered as a necessary precondition for associative learning in the context of this paradigm (see also Dawson \& Schell, 1987). As such, our data do not speak to reinstatement of more unconsciously acquired associations (e.g. Öhman \& Soares, 1998).

${ }^{3}$ In addition to the US-expectancy ratings and the fear and evaluative ratings, participants also indicated the extent to which each of the six pictures made them think of the US (Referential Rating, RR). This referential rating was included for explorative reasons only. Because we had no specific hypotheses concerning this measure in the context of the present research, the data for this rating will not further be reported and discussed. This rating was also assessed after extinction and reinstatement. Each time, an 11-point graphic rating scale was used, anchored by 'not at all' (0) and 'very much' (10). It was explained that this question did not pertain to the extent to which they had expected the US, but merely to the extent to which the CS 'made them think of the US'. The inclusion of the evaluative ratings was based on previous studies in which we employed the same conditioning preparation and in which research questions were more directly linked to the conditioning of stimulus valence (see also, Section 4).
} 
their evaluative ratings could have remained the same or could have changed as compared to the previous rating phase, but it was stressed that we were only interested in how they rated these stimuli at this very moment.

Reinstatement phase: This part of the experiment, immediately following the extinction phase, contained the crucial reinstatement manipulation. For the participants of the 'reinstatement condition' $(N=14)$, four unpredicted USs were presented (US-only trials). During a period of $95 \mathrm{~s}$, a US was scheduled after 15, 55, 85 and $95 \mathrm{~s}$. No CSs or tone probes were presented and the screen remained blank. For the participants of the 'control condition' $(N=14)$ no US-only presentations were scheduled. Participants of both groups were not informed that a US would be presented. Referring to the test phase that immediately followed the reinstatement phase, the experimenter only explained that face pictures and tones would be presented again, and to remain attentive during the stimulus presentations and to respond as fast as possible to the tone probes.

The experiment concluded with a post-reinstatement test phase which assessed the impact of the reinstatement procedure. Given that we tested under conditions of extinction, this phase consisted of a series of unreinforced CS + and CS- presentations. The crucial test block comprised $2 \mathrm{CS}+$ and $2 \mathrm{CS}-$ presentations. Because testing implied an extinction procedure - and thus might rapidly eliminate the effects of reinstatement - a tone probe was presented on each of the four trials of this first test block (1 CS + early, $1 \mathrm{CS}+$ late, $1 \mathrm{CS}-$ early and $1 \mathrm{CS}-$ late). After this test block, two other test blocks were presented, each comprising $7 \mathrm{CS}+$ and $7 \mathrm{CS}-$ presentations. On 8 of these 14 trials a probe was presented (2 CS + early, 2 CS + late, 2 CS - early and 2 CS - late). These two latter blocks were included to assess the rate at which possible reinstatement effects would extinguish as a consequence of the repeated CS- only presentations. The order of trials was randomized within each of these three test blocks.

After the test trials, US-expectancy ratings were again assessed, as well as evaluative and fear ratings. This was done twice for the US-expectancy and the fear ratings: once with reference to the first test block (US-expectancy 4a; FR4a) and once with reference to the last trials of the test phase (last trials of the third test block; US-expectancy 4b; FR4b). These separate ratings were included because it is to be expected that testing under extinction would eliminate possible reinstatement effects over the course of test trials. Because valence ratings were assumed to be less affected by this formal extinction procedure, evaluative ratings were only taken once after reinstatement (ER4).

Finally, participants rated the US for three characteristics. First, the (un)pleasantness of the US was rated on a graphic scale with ' $-50 /$ unpleasant' and ' $+50 /$ pleasant' as extremes, and ' $0 /$ neutral' as the neutral midpoint. The intensity of the US was assessed on a similar scale that ranged from 'light' over 'intense' to 'intolerable'. The extent to which the participant was startled by the US was appraised on a scale from 'not at all' over 'moderately' to 'very strongly'. When these ratings were completed, the electrodes were removed and the participant was debriefed and thanked.

\section{Results}

\subsection{Data reduction and analysis}

Two of the 30 participants failed to correctly select the CS + and the CS - from the set of six pictures. Because contingency awareness during acquisition was regarded as a minimal 
requirement for inclusion, these two participants were excluded from all further analyses. Hence, the final sample consisted of 28 participants, equally divided over the reinstatement group $(N=14)$ and the control group $(N=14)$.

The data from the verbal reports were analyzed using $2 \times 2 \times 2$ univariate analyses of variance (ANOVA) with condition (reinstatement group/control group) as between-subjects variable, and with CS-type $(\mathrm{CS}+/ \mathrm{CS}-$ ) and moment (combinations of pre-acquisition, post-acquisition, postextinction, and post-reinstatement) as within-subjects variables. The results were further examined using simple interactions and contrast analyses (two-tailed).

For the secondary probe reaction time task, all responses shorter than $200 \mathrm{~ms}$ or longer than $1200 \mathrm{~ms}$ were excluded to reduce the influence of outlier responses $(0.65 \%)$. Analyses of the response latencies were averaged for the acquisition block and the three extinction blocks separately. Because the effect of the reinstatement manipulation was tested 'under extinction', analyses of post-reinstatement response latencies were confined to the first test block. As already indicated, data of the two subsequent test blocks were included to compute the rate at which possible reinstatement effects would extinguish. All analyses concerning the reaction time data included probe position (early/late) as an extra within-subjects variable.

An alpha-level of .05 was used for all statistical tests. $p$-values will only be reported in the case of marginally significant effects $(.05<p<.10)$.

\subsection{Characteristics of the US}

Participants rated the US as unpleasant $(M=-34.1)$ and intense $(M=62.1)$, and indicated that they were moderately to strongly startled by the US $(M=68.1)$. There were no differences between the two participant groups in the way the US was experienced, all $t(26)<1$, n.s. Hence, we can conclude that the US was experienced as a rather aversive stimulus.

\subsection{Acquisition data}

During acquisition the CS + became a valid predictor for the US. The mean US-expectancy score was 95 for the $\mathrm{CS}+$ and 4.3 for the $\mathrm{CS}-, F(1,26)=526, M S e=2.19$. There were no group differences with respect to the US-expectancy ratings, $F<1$. The fact that participants had learned the CS-US contingency was also apparent from the data of the secondary reaction time task. The Condition $\times$ CS-type $(\mathrm{CS}+/ \mathrm{CS}-) \times$ Probe position (Early/Late) ANOVA revealed a main effect of CS-type, $F(1,26)=6.11, M S e=12156$. Response latencies to the tone probes were significantly longer when these probes were presented during the CS $+(M=613)$, as compared to probe presentations during the $\mathrm{CS}-(M=561)$. There were no main effects or interactions concerning probe position or condition, all $F<1.04$.

In addition to the fact that the $\mathrm{CS}+$ had become a meaningful predictor for the occurrence of the US, the acquisition procedure had also led to significant shifts in the evaluative meaning of the $\mathrm{CS}+$ and $\mathrm{CS}-$. After acquisition there was a highly significant difference between the valence ratings of the $\mathrm{CS}+(M=-49.6)$ and the $\mathrm{CS}-(M=18.2), F(1,26)=41.05, M S e=15.7$, whereas there was no difference before acquisition, $F(1,26)<1, M_{\mathrm{CS}+}=-0.71, M_{\mathrm{CS}-}=-1.07$ (see Table 1). The significant CS-type $(\mathrm{CS}+/ \mathrm{CS}-) \times$ Moment $(\mathrm{ER} 1 / \mathrm{ER} 2)$ interaction, $F(1,26)=$ $40.66, M S e=8.01$, can mainly be attributed to the $\mathrm{CS}+$ becoming more negative from ER 1 to 
Table 1

Mean ratings (US-expectancy, fear, evaluative) and mean response latencies (early probes, late probes, total) as a function of moment (pre-acquisition, post-acquisition, post-extinction, post-reinstatement) and CS-type (CS,$+ \mathrm{CS}-$ )

\begin{tabular}{|c|c|c|c|c|c|c|c|c|c|c|}
\hline & \multirow{2}{*}{\multicolumn{2}{|c|}{ Pre-acquisition }} & \multirow{2}{*}{\multicolumn{2}{|c|}{$(\text { Post- })^{\mathrm{a}}$ acquisition }} & \multirow{2}{*}{\multicolumn{2}{|c|}{ (Post-) extinction }} & \multicolumn{4}{|c|}{ (Post-) reinstatement } \\
\hline & & & & & & & \multicolumn{2}{|c|}{ Reinstatement group } & \multicolumn{2}{|c|}{ Control group } \\
\hline & $\mathrm{CS}+$ & $\mathrm{CS}-$ & $\mathrm{CS}+$ & $\mathrm{CS}-$ & $\mathrm{CS}+$ & $\mathrm{CS}-$ & $\mathrm{CS}+$ & $\mathrm{CS}-$ & $\mathrm{CS}+$ & $\mathrm{CS}-$ \\
\hline \multicolumn{11}{|l|}{ Ratings } \\
\hline US-expectancy & & & 95.0 & 4.3 & 11.8 & 1.8 & 80.0 & 42.9 & 22.9 & 31.4 \\
\hline Fear & 0.5 & 0.4 & 5.6 & 0.5 & 1.5 & .2 & 5.6 & 3.2 & 1.6 & 2.1 \\
\hline Evaluative & -1 & -1 & -49.6 & 18.2 & -32.1 & 21.1 & -39.3 & -0.7 & -20.0 & 6.4 \\
\hline \multicolumn{11}{|l|}{$R T$-data ${ }^{\mathrm{b}}$} \\
\hline Total & & & 613 & 561 & 399 & 433 & $503^{\mathrm{c}}$ & 455 & 499 & 457 \\
\hline Early probe & & & 630 & 569 & 388 & 416 & 502 & 436 & 513 & 486 \\
\hline Late probe & & & 596 & 554 & 410 & 451 & 504 & 474 & 486 & 428 \\
\hline
\end{tabular}

For the post-reinstatement data, means are presented for the reinstatement group and the control group separately. The (post-) reinstatement data are related to the first test block.

${ }^{a}$ The data for the ratings were collected immediately after each phase, whereas the reaction time data were collected online (i.e. during the phase).

${ }^{\mathrm{b}}$ The mean reaction time data that are reported for the extinction phase are based on the last of the three extinction blocks.

${ }^{\mathrm{c}}$ The reinstatement data for the probe task are based on 26 participants (because of missing data for two participants).

ER2, $F(1,26)=60.86, M S e=5.5$. There was a marginally significant tendency for the CS - to becoming more positive, $F(1,26)=3.99, M S e=13.03, p=.057$. The acquisition effect in the valence ratings was not different for both groups, $F<1$.

Finally, conditioning was also apparent from the data of the Fear Thermometer, which showed that after acquisition, the CS + elicited significantly more fear $(M=5.61)$ than the CS$(M=0.50), \quad F(1,26)=139.3, \quad M S e=2.62$. No similar difference was observed prior to acquisition, $F(1,26)<1, M_{\mathrm{CS}+}=0.46, M_{\mathrm{CS}-}=0.43$. The significant CS-type $(\mathrm{CS}+/ \mathrm{CS}-) \times \mathrm{Mo}-$ ment $(\mathrm{FR} 1 / \mathrm{FR} 2)$ interaction, $F(1,26)=122.61, M S e=1.47$, is solely due to the CS + becoming more fearful from FR1 to FR2, $F(1,26)=124.68, M S e=2.97$. No similar shift was observed for the $\mathrm{CS}-, F<1$. As was the case for all other acquisition effects, the shifts in the fear ratings were the same for both participant groups, $F<1$.

Based on these data, we can conclude that the acquisition procedure has been successful in that the CS + became (a) a valid predictor for the US, and (b) induced significantly more fear than the $\mathrm{CS}-$. This acquisition effect was also evident from the reaction time data. In addition the CS + acquired a significantly more negative valence.

\subsection{Extinction data}

After the extinction phase, the participants were asked to provide US-expectancy ratings for the $\mathrm{CS}+$ and the $\mathrm{CS}-$ for the second time. As expected, there was a significant interaction between 
CS-type and moment (post-acquisition/post-extinction), $F(1,26)=206.9, \quad M S e=2.21$. The extinction procedure led to a dramatic change in the extent to which a US was expected following the $\mathrm{CS}+, F(1,26)=327.19, M S e=2.96, M_{\text {post-acquisition }}=95, M_{\text {post-extinction }}=11.8$. For the CS- there was no change in US-expectancy from post-acquisition to post-extinction, $F(1,26)=1.98, \quad M S e=0.44, \quad n . S ., \quad M_{\text {post-acquisition }}=4.2, \quad M_{\text {post-extinction }}=1.8$. It is however important to note that even though the extinction procedure had a massive impact on the extent to which the CS + led to the active expectancy of the US $(F=327)$, there remained a small, but nevertheless significant difference between the $\mathrm{CS}+$ and $\mathrm{CS}-$ at the post-extinction ratings; $F(1,26)=9.17, M S e=1.53$. None of the interactions with the condition variable was significant, $F<1$.

The reaction time data that were registered during extinction no longer revealed a differential responding to the probes during $\mathrm{CS}+$ and $\mathrm{CS}-, F(1,26)<1, M_{\mathrm{CS}+}=428, M_{\mathrm{CS}-}=431$. Also, an additional ANOVA that included the acquisition block and the last extinction block, revealed a significant interaction between block (acquisition block, last extinction block) and CS-type, $F(1,26)=12.97, M S e=7954$. Again, the variable 'condition' did not interact with any of these effects, $F<1$.

In contrast with the expectancy ratings and the secondary RT task, the extinction procedure only had a marginally significant impact on the conditioned stimulus valence. The relevant CStype $(\mathrm{CS}+/ \mathrm{CS}-) \times$ Moment $(\mathrm{ER} 2 / \mathrm{ER} 3)$ interaction only approached significance, $F(1,26)=$ $3.95, M S e=3.80, p=.06$. Also, there remained a highly significant difference in the evaluative ratings of both stimuli after extinction, $M_{\mathrm{CS}+}=-32.1, M_{\mathrm{CS}-}=21.1, F(1,26)=38.17, M S e=$ 10.39 (see Table 1).

For the Fear Thermometer, the significant interaction between CS-type and moment (postacquisition/post-extinction) revealed a marked effect of extinction, $F(1,26)=72.62, M S e=1.43$. The CS + no longer elicited as much anxiety after extinction $(M=1.46)$ as compared to the postacquisition ratings $(M=5.61), F(1,26)=84.83, M S e=2.83$, while a similar shift was absent for the CS- $F<1, M_{\text {post-acquisition }}=0.50, M_{\text {post-extinction }}=0.21$. Nevertheless, there remained a significant difference between $\mathrm{CS}+$ and $\mathrm{CS}-$ at the post-extinction ratings, $F(1,26)=20.18$, $M S e=1.08$. As was the case for all prior analyses, for the fear and evaluation ratings none of the relevant effects interacted with condition (reinstatement group/control group), all $F$ 's $<1$.

In sum, these results indicate that the extended series of extinction trials has had a strong impact on the way in which the CS + was experienced. Not only was the CS + no longer considered as a good predictor of the US (as evidenced by ratings and response latencies), but the amount of fear that is induced by the CS + also declined considerably. Finally, and in contrast to the strong extinction effects for US-expectancy and fear, there was only a tendency towards an extinction effect for the acquired evaluative meaning of the CS's.

\subsection{Reinstatement data}

A three-way interaction of condition (reinstatement group/control group), moment (postextinction/post-reinstatement) and CS-type $(\mathrm{CS}+/ \mathrm{CS}-)$ constitutes the crucial test for a reinstatement effect in the US-expectancy ratings. This interaction was significant, $F(1,26)=$ 9.71, $M S e=3.31$. Simple interactions (moment $\times$ condition) at each level of the CS-type variable revealed that the reinstatement manipulation had differentially affected responding to the $\mathrm{CS}+$, 
$F(1,26)=26.11, M S e=3.85$. Further inspection of the data for the CS + showed a strong increase in US-expectancy for the CS + from post-extinction $(M=13.6)$ to post-reinstatement $(M=80)$ in the reinstatement group, $F(1,26)=80.28, M S e=3.85$, but not in the control group, $F(1,26)=3.01, M S e=3.85, p=.10, M_{\text {post-extinction }}=10, M_{\text {post-reinstatement }}=22.9$. In line with predictions, for the $\mathrm{CS}-$, both groups showed a comparable pattern of data, $F<1$ (see Table 1 ).

Another way of looking at the reinstatement effect is based on simple interactions (moment $\times$ CS-type) at each level of the between-subjects variable, which informs about the effect of the reinstatement phase in both groups separately. As predicted, a significant moment by CS-type interaction was observed for the reinstatement group, $F(1,13)=15.95, M S e=1.45$, but not for the control group, $F(1,13)=1,99, M S e=5.17$, n.s. A graphic display of this reinstatement effect can be found in Fig. 1. As indicated by $\mathrm{CS}+/ \mathrm{CS}-$ difference scores, both groups showed equal amounts of acquisition and extinction, but whereas there was a clear 'reinstatement' of conditioned responding $(\mathrm{CS}+/ \mathrm{CS}-$ difference) in the experimental group, no return of the $\mathrm{CS}+/ \mathrm{CS}-$ differentiation was present in the control group.

A similar effect of the reinstatement procedure was found in the fear ratings (see Fig. 2). The critical three-way interaction approached significance, $F(1,26)=3.67, M S e=2.49, p=.06$. Nevertheless, simple interactions (moment $\times$ condition) showed the same pattern of results as was observed for the US-expectancy ratings. As expected, this interaction was not significant for the $\mathrm{CS}-$ ratings, $F<1$. But, for the $\mathrm{CS}+$ the crucial interaction was significant, $F(1,26)=16.82$, $M S e=1.96$. Further inspection of the data showed a strong increase in the fear ratings for the $\mathrm{CS}+$ from post-extinction $(M=1.93)$ to post-reinstatement $(M=5.64)$ in the reinstatement group, $F(1,26)=49.19, M S e=1.96$, but not in the control group, $F(1,26)=1.47$, $M S e=1.96$, n.s., $M_{\text {post-extinction }}=1.00, M_{\text {post-reinstatement }}=1.64$.

For the reaction time data the crucial three-way interaction was not significant, $F(1,24)<1$. Overall, there was a return of conditioned responding after the reinstatement phase, $F(1,24)=8.75{ }^{4} \quad M S e=10340$. Response latencies during presentation of the $\mathrm{CS}+$ were significantly slower after reinstatement, $F(1,24)=64.35, M S e=4415, \quad M_{\text {post-extinction }}=396$, $M_{\text {post-reinstatement }}=501$, while a similar shift was absent for the CS $-, F<1, M_{\text {post-extinction }}=435$, $M_{\text {post-reinstatement }}=456$. Against expectation, this pattern of data was not different for both conditions (see Table 1).

The results of the reinstatement phase demonstrate that the mere presentation of the US in the absence of the CS can lead to a 'reinstated' responding to the CS + . This was evident from both the fear ratings and the US-expectancy ratings. The data of the probe reaction time task were less differentiated.

\subsection{Extinction of the reinstatement effects}

Because the post-reinstatement test trials are actually additional extinction trials (no US's were presented during testing), the data from the second and third test block allow to investigate whether the observed reinstatement effect survives further extinction. After the three blocks of test trials, fear and US-expectancy ratings were not only assessed with respect to the first test block

\footnotetext{
${ }^{4}$ The data of these analyses are based on 26 of the 28 participants, given that there was a missing observation for the post-reinstatement trials for two participants.
} 


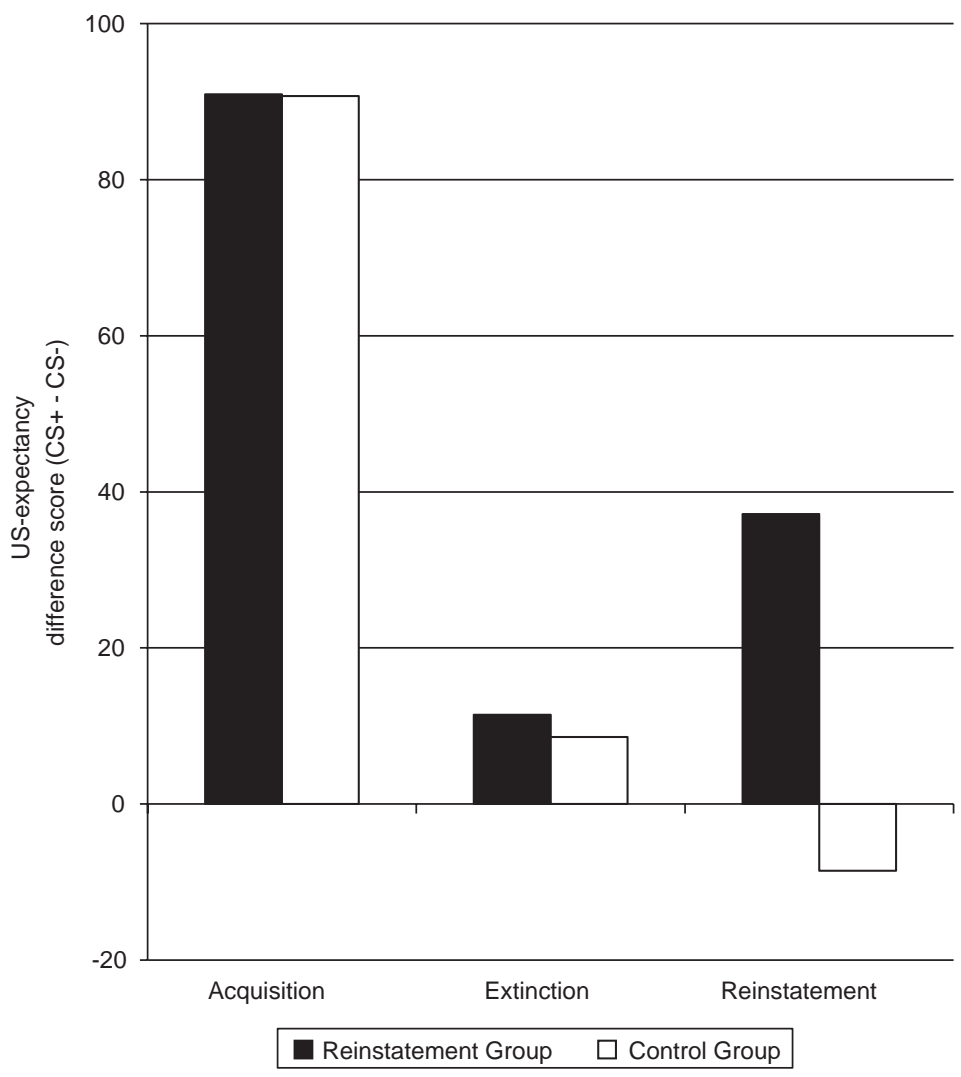

Fig. 1. Differences in US-expectancy for the CS + and CS-, as a function of condition (reinstatement group, control group) and moment (post-acquisition, post-extinction, post-reinstatement) [difference score $=\mathrm{CS}+-\mathrm{CS}-$ ].

(FR4a; US-expectancy 4a), but also with respect to the last trials from the test series (FR4b; USexpectancy $4 \mathrm{~b}$ ). When these latter data were entered into the analysis, instead of the ratings that referred to the first test block, the interaction between condition (reinstatement group/control group), moment (post-extinction/post-reinstatement) and CS-type (CS + $/ \mathrm{CS}-$ ) no longer reached significance for the US-expectancy ratings, $F(1,26)<1$, or the fear ratings, $F(1,26)=1,56, p=$ .22 . This indicates that the observed reinstatement effect quickly dissipates when further CS-only trials are presented.

\section{Discussion}

In the present study, a significant reinstatement effect was observed for fear ratings and ratings of US-expectancy. Using a differential fear conditioning procedure, participants first underwent an acquisition training during which a picture $\mathrm{CS}(\mathrm{CS}+)$ was contingently followed by an aversive electrocutaneous stimulus, while a second stimulus (CS-) was never followed by the US. After a subsequent extinction phase, for half of the participants (reinstatement group) the US was 


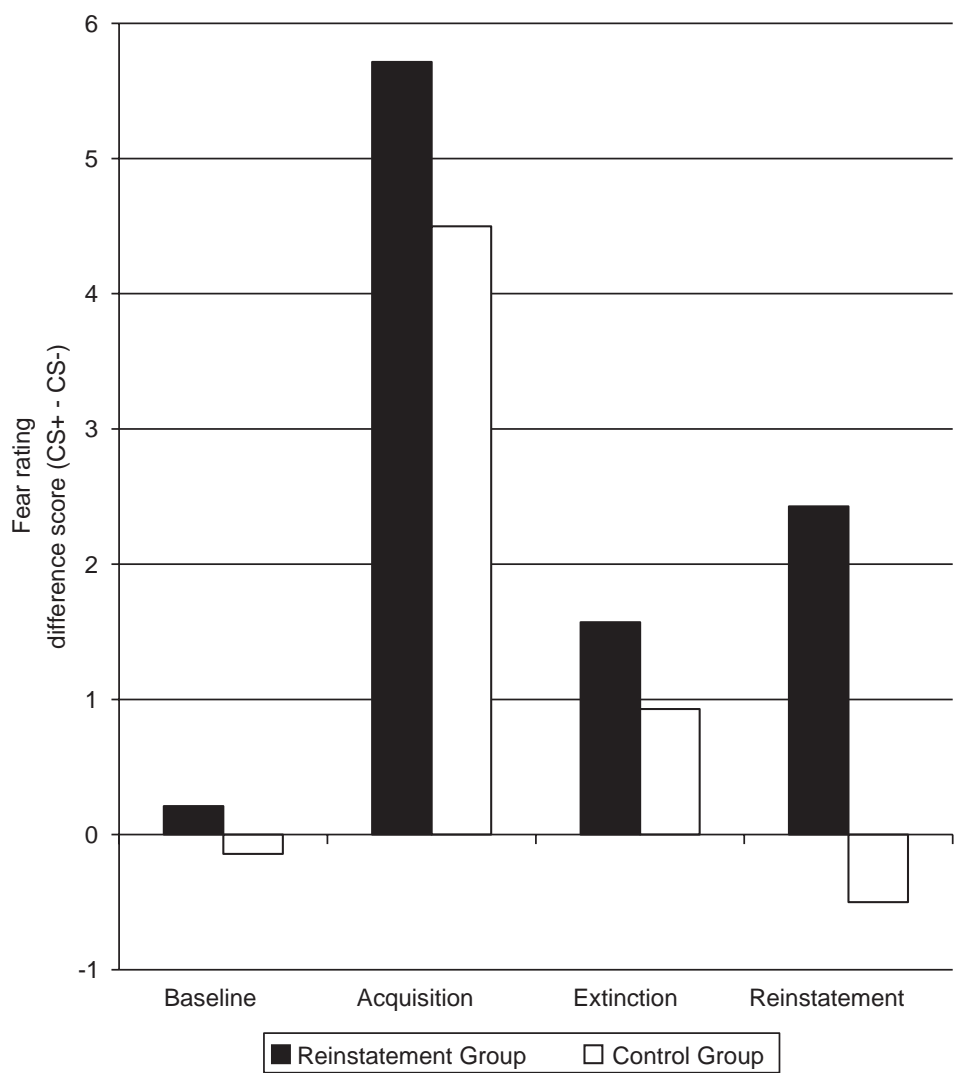

Fig. 2. Differences in fear ratings for the $\mathrm{CS}+$ and $\mathrm{CS}-$, as a function of condition (reinstatement group, control group) and moment (pre-acquisition, post-acquisition, post-extinction, post-reinstatement) [difference score $=\mathrm{CS}+-\mathrm{CS}-]$.

presented four times in the absence of the $\mathrm{CS}+$. For the control group there were no additional US-only presentations. This reinstatement procedure led to a selective increase of fear and USexpectancy ratings for the $\mathrm{CS}+$ (but not the $\mathrm{CS}-$ ) in the reinstatement group. A similar effect was absent in the control group.

To our knowledge, this is the first demonstration of reinstatement of fear responses in humans. From a clinical point of view, this reinstatement effect might relate to one of the mechanisms underlying ROF. Akin to the renewal studies that show that a change of context might be the basis for a ROF after extinction, the present results suggest that the mere confrontation with the US after extinction might be a sufficient basis for reappearance of fear (and US-expectancy). A clinical example would be the patient (a mailman) who acquired a fear of elevators after multiple experiences of a panic attack in such small spaces, and who subsequently underwent exposure treatment for these complaints. In spite of the success of the exposure treatment, reinstatement would be evident when this person would experience one or more new panic attacks (US) in the absence of the original CS (e.g. a new panic attack when sitting at his desk at the post-office), and this would subsequently lead to a (partial) restoration of his fear of elevators. 
Although the data constitute a clear demonstration of reinstatement in human fear conditioning, one of the limitations of the present study is that fear responses were observed only at the subjective, verbal level. Future studies could include measures of fear that are situated at the physiological (e.g. skin conductance response) or the behavioral level (e.g. avoidance behavior). Also, the present data are confined to participants that were aware of the crucial CS-US contingency after acquisition. As such, the data do not speak to reinstatement of more unconsciously acquired associations (e.g. Öhman \& Soares, 1998). Finally, future research might investigate reinstatement for fear-relevant stimuli and possible differences in the preconditions for reinstatement with fear- and fear-irrelevant stimuli (Öhman \& Mineka, 2001).

It is interesting to note that the reinstatement effect was observed despite a lengthy extinction procedure (i.e. three times the amount of acquisition trials) and in spite of a limited number of US-only presentations. Future research will inform about the boundaries of this reinstatement effect. Recent work by Denniston, Chang, and Miller (2003), for instance, shows that massive extinction treatment can attenuate renewal effects (i.e. a total of 600 extinction trials over three consecutive extinction sessions), whereas after moderate extinction training (i.e. 120 extinction trials) no such attenuation was observed. It remains to be tested whether reinstatement effects are similarly unaffected by a relative increase of the number of extinction trials. If so, this would suggest that one should not look for methods of prevention of ROF (due to reinstatement) in extending the number of exposure sessions. Other alternatives may be found within the reinstatement literature. For example, research by Rauhut, Thomas, and Ayres (2001) supports the effectiveness of inserting US-only presentations in the extinction phase as a way of diminishing the effect of reinstatement. Or, as suggested by Bouton (1988), prolonged exposure to the reinstatement context might also prevent ROF.

Given that therapeutic suggestions like these are based on animal research, their relevance for human fear learning should be further examined. The differential conditioning paradigm that was employed in this study might be used as a laboratory analogue to tackle a number of research questions before these are implemented in more clinical research designs (e.g. with patient groups). An advantage of this conditioning procedure is that one has complete control over the acquisition and extinction of the fear responses. This will allow interpreting possible differences in the restoration of fear between both groups more unambiguously as an effect of the reinstatement procedure. This would not be possible in a more clinical research paradigm (e.g. reinstatement after exposure treatment for certain fears) in which less or nothing is known about the circumstances of the original fear acquisition and the nature of the original US. Also, ethical concerns would preclude studying reinstatement in more clinical settings (because of the nature of the to be presented USs).

Besides research efforts directed at unveiling procedures to reduce/prevent reinstatement effects, future studies should also focus on a better understanding of the mechanisms that are responsible for reinstatement in humans. In particular, the role of the reinstatement context and the nature of the reinstatement US should be clarified. Related to this latter issue, it remains an open question whether the reinstatement US should be the same as the US involved in the acquisition. Jacobs and Nadel (1985), for instance, point to the clinical observation that an unrelated stressful period or event sometimes triggers old fears and phobias from which the person had been unchained for quite some time. The already mentioned study of Rescorla and Heth (1975) also seems to support the idea that the reinstatement US does not need to be identical 
to the one involved in acquisition. Future research will have to test whether these findings are replicable for fear reinstatement in humans. With respect to the role of the reinstatement context, it is crucial to note that the dominant models emphasize the importance of the context in elevating conditioned responding during the test for reinstatement. This is clearly illustrated by the observation that no or less reinstatement is found when the reinstating US is presented in a context different from the test context (e.g. Bouton, 1984). Different types of processes have been put forward to explain this apparent context-dependency of reinstatement (see Delamater, 1997). The generality with which the laboratory phenomenon of reinstatement can be translated to clinical reality will depend in part on the types of processes that are involved in this contextual influence and on the absoluteness of this contextual control. If there is a complete contextual control, in the aforementioned example of the mailman with elevator phobia, one would only expect a ROF for elevators that are entered in the context of his job as a mailman (the reinstating US was encountered in the context of his work). If, however, in line with recent animal data from Richardson and colleagues (Richardson, Duffield, Bailey \& Westbrook, 1999), reinstatement can also be demonstrated when shock USs are presented in a context that is different from the test context, one would predict a reinstatement of elevator fear in any type of context. The fact that there may be differences in the extent to which certain contexts resemble other contexts (generalization gradient) and the fact that contexts should not only be defined in terms of physical environment (also time-related, emotions, drug induced states), further point to the multiple facets that will be faced by future research on contextual control of fear reinstatement in humans.

An aspect of the present results that deserves some further discussion, relates to the data of the secondary probe reaction time task. Replicating the findings of Dawson et al. (1982) and Lipp et al. (1993), we observed significantly slower responses to tone probes that were presented during the $\mathrm{CS}+$ as compared to the CS-. This effect was independent of probe position (early versus late probe) and disappeared throughout extinction. But, although the means were in the predicted direction (see Table 1), the reaction time data did not show the reinstatement pattern as was observed in the fear ratings and the US-expectancy ratings. This absence of a reinstatement effect might be due to the small number of observations during the test phase. In fact, there was only one observation for each cell of the design (1 CS + early, $1 \mathrm{CS}+$ late, $1 \mathrm{CS}-$ early and $1 \mathrm{CS}-$ late). Future studies shall inform us whether this null-effect can indeed be attributed to a lack of power. One alternative explanation might be that, because testing took place under extinction, already after the first presentation of the CS + the participant could notice that the CS + was not followed by the US. If reinstatement effects are easily weakened by subsequent CS-only presentations, as is suggested by the data from the present fear and US-expectancy ratings as well as by animal studies (e.g. Bouton, 1984), it might be that the mere assessment of reinstatement in the reaction times (which necessarily implies unreinforced presentations of the CS + and $\mathrm{CS}-$ ) already weakens the reinstatement effect. From a clinical point of view, these data also suggest that although reinstatement might be the basis for ROF, exposing oneself again to the fearinducing stimuli and refraining from avoidance behavior will quite rapidly lessen the reinstatement effect.

Finally, and somewhat unrelated to the reinstatement question, the present results replicate previous research from our lab that shows that aversive conditioning also endows the CS + with a negative affective meaning (Hermans, Baeyens, \& Eelen, 2003; Hermans et al., 2002b), which seems to be less strongly altered by a procedure of extinction than the acquired predictive value and the 
amount of fear elicited by the CS + (Hermans et al., 2002a). In clinical practice, this might lead to the situation that after extinction the patient no longer fears the CS (e.g. open spaces, elevator, supermarket) and no longer actively expects the CS to be followed by a US (e.g. a panic attack), but still strongly dislikes the CS. To the extent that negative valence is associated with response tendencies in the category of 'escape/avoidance', such a residual negative stimulus valence might, by itself, form a source for ROF. Additional exploratory analyses revealed some evidence for this hypothesis. A significant correlation was observed between the affective meaning of the CS + after extinction and a general index ${ }^{5}$ of ROF, $r(28)=-.42, p<.05$, indicating that the more negative the $\mathrm{CS}+$ was rated at the end of the extinction phase, the more ROF was observed (irrespective of the reinstatement manipulation). Similar correlations were not found for post-extinction fear ratings, $r(28)=-.002, p=.992$, or post-extinction US-expectancy ratings (for the CS + ), $r(28)=.093$, $p=.636$, which suggests that stimulus valence is indeed the crucial element here. These preliminary results indicate that negative stimulus valence might be associated with higher levels of ROF. Future research will have to further investigate this impact of (negative) stimulus valence, as well as possible interactions between stimulus valence and other sources of ROF (e.g. reinstatement).

\section{References}

Abramowitz, J. S. (1996). Variants of exposure and response prevention in the treatment of obsessive compulsive disorder: a meta-analysis. Behavior Therapy, 27, 583-600.

Bouton, M. E. (1984). Differential control by context in the inflation and reinstatement paradigms. Journal of Experimental Psychology: Animal Behaviour Processes, 10, 56-74.

Bouton, M. E. (1988). Context and ambiguity in the extinction of emotional learning: implications for exposure therapy. Behaviour Research and Therapy, 26, 137-149.

Bouton, M. E. (1998). The role of context in classical conditioning: some implications for cognitive behavior therapy. In O’Donahue, W. T. (Ed.), Learning and Behaviour Therapy. Boston, MA: Allyn \& Bacon, Inc.

Bouton, M. E., \& Bolles, R. C. (1979). Role of conditioned contextual stimuli in reinstatement of extinguished fear. Journal of Experimental Psychology: Animal Behavior Processes, 5, 368-378.

Bouton, M. E., Mineka, S., \& Barlow, D. H. (2001). A modern learning theory perspective on the etiology of panic disorder. Psychological Review, 108, 4-32.

Bouton, M. E., \& Peck, C. A. (1989). Context effects on conditioning, extinction, and reinstatement in an appetitive conditioning preparation. Animal Learning \& Behavior, 17, 188-198.

Bouton, M. E., \& Swartzentruber, D. (1991). Sources of relapse after extinction in Pavlovian and instrumental learning. Clinical Psychology Review, 11, 123-140.

Clum, G. A., Clum, G., \& Surls, R. (1993). A meta-analysis of treatments for panic disorder. Journal of Consulting and Clinical Psychology, 61, 317-326.

Cox, B. J., Endler, N. S., Lee, P. S., \& Swinson, R. P. (1992). A meta-analysis of treatments for panic disorder with agoraphobia: imipramine, alprazolam, and in vivo exposure. Journal of Behavior Therapy and Experimental Psychiatry, 23, 175-182.

Cox, B. J., Swinson, R. P., Morrison, B., \& Lee, P. S. (1993). Clomipramine, fluoxetine, and behavior therapy in the treatment of obsessive-compulsive disorder: a meta-analysis. Journal of Behavior Therapy and Experimental Psychiatry, 24, 149-153.

\footnotetext{
${ }^{5}$ This index is based on the fear ratings for the CS + and CS- after extinction (FR3) and during the test phase (FR4a). The index, $\left[\left(\mathrm{FR} 4 \mathrm{a}_{\mathrm{CS}+}-\mathrm{FR} 4 \mathrm{a}_{\mathrm{CS}-}\right)-\left(\mathrm{FR} 3_{\mathrm{CS}+}-\mathrm{FR} 3_{\mathrm{CS}-}\right)\right]$, reflects the increase of fear for the CS + from postextinction to test, and is weighted against a possible similar increase for the CS-. The higher the index, the more return of fear for the $\mathrm{CS}+$ as compared to the CS-.
} 
Davey, G. C. L. (1992). Classical conditioning and the acquisition of human fears and phobias: a review and synthesis of the literature. Advances in Behaviour Research and Therapy, 14, 29-66.

Davey, G. C. L. (1997). A conditioning model of phobias. In Davey, G. C. L. (Ed.), Phobias. A handbook of theory, research and treatment (pp. 301-322). Chichester: Wiley.

Davey, G. C. L. (2002). 'Nonspecific' rather than 'nonassociative' pathways to phobias: a commentary on Poulton and Menzies. Behaviour Research and Therapy, 40, 151-158.

Dawson, M. E., \& Schell, A. M. (1987). Human autonomic and skeletal classical conditioning: The role of conscious cognitive factors. In Davey, G. (Ed.), Cognitive processes and Pavlovian conditioning in humans (pp. 27-55). Chichester, England: Wiley.

Dawson, M. E., Schell, A. M., Beers, J. R., \& Kelly, A. (1982). Allocation of cognitive processing capacity during human autonomic classical conditioning. Journal of Experimental Psychology, 111, 273-294.

Delamater, A. R. (1997). Selective reinstatement of stimulus-outcome associations. Animal Learning \& Behavior, 25, 400-412.

Denniston, J. C., Chang, R. C., \& Miller, R. R. (2003). Massive extinction treatment attenuates the renewal effect. Learning and Motivation, 34, 68-86.

García-Gutiérrez, A., \& Rosas, J. M. (2003). Empirical and theoretical implications of additivity between reinstatement and renewal after interference in causal learning. Behavioural Processes, 63, 21-31.

Eelen, P., Hermans, D., \& Baeyens, F. (2001). Learning perspectives on anxiety disorders. In Griez, E. J. L., Faravelli, C., Nutt, D., \& Zohar, J. (Eds.), Anxiety disorders: an introduction to clinical management and research (pp. 249-264). London: Wiley.

Feske, U., \& Chambless, D. L. (1995). Cognitive behavioral versus exposure only treatment for social phobia: a metaanalysis. Behavior Therapy, 26, 695-720.

Gunther, L. M., Denniston, J. C., \& Miller, R. R. (1998). Conducting exposure treatment in multiple contexts can prevent relapse. Behaviour Research and Therapy, 36, 75-91.

Hermans, D. (1997). The Need to Evaluate Scale (NES). Unpublished authorised Dutch translation.

Hermans, D., Baeyens, F. \& Claryse, J. (2000). Affect (Version 1.0) [Computer software, University of Leuven, Belgium; retrieved from http://www.psy.kuleuven.ac.be/leerpsy/affect].

Hermans, D., Baeyens, F., \& Eelen, P. (2003). On the acquisition and activation of evaluative information in memory: evaluative learning and affective priming combined. In Musch, J., \& Klauer, K. C. (Eds.), The psychology of evaluation: affective processes in cognition and emotion (pp. 139-168). Mahwah, NJ: Lawrence Erlbaum.

Hermans, D., Crombez, G., Vansteenwegen, D., Baeyens, F., \& Eelen, P. (2002a). Expectancy-learning and evaluative learning in human classical conditioning: differential effects of extinction. In Shohov, S. P. (Ed.), Advances in Psychology Research, Vol. 12 (pp. 17-41). New York: Nova Science Publishers, Inc.

Hermans, D., Spruyt, A., \& Eelen, P. (2003). Automatic affective priming of recently acquired stimulus valence: priming at SOA 300 but not at SOA 1000. Cognition and Emotion, 17, 83-99.

Hermans, D., Vansteenwegen, D., Crombez, G., Baeyens, F., \& Eelen, P. (2002b). Expectancy-learning and evaluative learning in human classical conditioning: affective priming as an indirect and unobtrusive measure of conditioned stimulus valence. Behaviour Research and Therapy, 40, 217-234.

Jacobs, W. J., \& Nadel, L. (1985). Stress-induced recovery of fears and phobias. Psychological Review, 92, 512-531.

Jarvis, W. B. G., \& Petty, R. E. (1996). The need to evaluate. Journal of Personality and Social Psychology, 70, 172-194.

Lipp, O. V., Siddle, D. A. T., \& Dall, P. J. (1993). Effects of miscuing on Pavlovian conditioned responding and on probe reaction time. Australian Journal of Psychology, 45, 161-167.

Mineka, S., Mystkowski, J. L., Hladek, D., \& Rodriguez, B. I. (1999). The effects of changing contexts on return of fear following exposure therapy for spider fear. Journal of Consulting and Clinical Psychology, 67, 599-604.

Mystkowski, J. L., Craske, M. G., \& Echiverri, A. M. (2002). Treatment context and return of fear in spider phobia. Behaviour Therapy, 33, 399-416.

Öhman, A., \& Mineka, S. (2001). Fear, phobias and preparedness: toward an evolved module of fear and fear learning. Psychological Review, 108, 483-522.

Öhman, A., \& Soares, J. J. F. (1998). Emotional conditioning to masked stimuli: expectancies for aversive outcomes following non-recognized fear-relevant stimuli. Journal of Experimental Psychology: General, 127, 69-82.

Öst, L. G. (1989). One-session treatment for specific phobias. Behaviour Research and Therapy, 27, 1-7. 
Rachman, S. J. (1979). The return of fear. Behaviour Research and Therapy, 17, 164-165.

Rachman, S. J. (1989). The return of fear: review and prospect. Clinical Psychology Review, 9, 147-168.

Rachman, S. J., \& Whittal, M. (1989). The effect of an aversive event on the return of fear. Behaviour Research and Therapy, 27, 513-520.

Rauhut, A. S., Thomas, B. L., \& Ayres, J. J. B. (2001). Treatments that weaken Pavlovian conditioned fear and thwart its renewal in rats: implications for treating human phobias. Journal of Experimental Psychology: Animal Behavior Processes, 27, 99-114.

Rescorla, R. A. (1996). Preservation of Pavlovian associations through extinction. Quarterly Journal of Experimental Psychology, 49B, 245-258.

Rescorla, R. A., \& Heth, C. D. (1975). Reinstatement of fear to an extinguished conditioned stimulus. Journal of Experimental Psychology: Animal Behavior Processes, 1, 88-96.

Richardson, R., Duffield, T. Q., Bailey, G. K., \& Westbrook, R. F. (1999). Reinstatement of fear to an extinguished conditioned context. Animal Learning \& Behavior, 27, 399-415.

Schachtman, T. R., Gustavson, K. K., Chelonis, J. J., \& Bourne, M. J. (1992). Effects of US reinstatement on the potential of an extinguished CS to attenuate manifest learning about another CS. Learning and Motivation, 23, $250-268$.

Spradlin, J. E., Fixsen, D. L., \& Girardeau, F. L. (1969). Reinstatement of an operant response by the delivery of reinforcement during extinction. Journal of Experimental Child Psychology, 7, 96-100.

Spradlin, J. E., Girardeau, F. L., \& Hom, G. L. (1966). Stimulus properties of reinforcement during extinction of a free operant response. Journal of Experimental Child Psychology, 4, 369-380.

Taylor, S. (1996). Meta-analysis of cognitive-behavioral treatment for social phobia. Journal of Behavior Therapy and Experimental Psychiatry, 27, 1-9.

Trull, T. J., Nietzel, M. T., \& Main, A. (1988). The use of meta-analysis to assess the clinical significance of behavior therapy for agoraphobia. Behavior Therapy, 19, 527-538.

Vansteenwegen, D., Hermans, D., Vervliet, B., Francken, G., Beckers, T., Baeyens, F., \& Eelen, P. (2003). Return of fear in a human differential conditioning paradigm caused by a return to the original acquisition context. (Manuscript submitted for publication).

Westbrook, R. F., Iordanova, M., McNally, G., Richardson, R., \& Harris, J. A. (2002). Reinstatement of fear to an extinguished conditioned stimulus: two roles for context. Journal of Experimental Psychology: Animal Behavior Processes, 28, 97-110. 